\title{
Very late stent thrombosis- An emerging predicament
}

\author{
Nishith Chandra and Ranjan Modi* \\ Fortis Escorts Heart Institute, Okhla, New Delhi
}

\begin{abstract}
Very late stent thrombosis is a known entity in interventional cardiology. Previous literature has mentioned very late stent thrombosis as a complication associated with drug-eluting stents. We report the case of a 62-year-old man with Non-ST segment-elevation myocardial infarction 5 years after drug-eluting stent implantation.

Optical coherence tomograms of the lesion showed that the focal incomplete endothelialization of the stent struts was the most probable cause. To our knowledge, this is the longest reported intervening period between stent insertion and the development of an acute coronary event secondary to very late stent thrombosis reported in India.
\end{abstract}

\section{Learning objective}

Very late stent thrombosis illuminates the uncertainties surrounding the ideal duration of antiplatelet therapy in patients with drug eluting stents. Present guidelines recommend the discontinuation of dual antiplatelet therapy in patients after one year. Thus, this case illustrates the challenge faced in optimized individualized duration of antiplatelet.

\section{Introduction}

Stent thrombosis has been the most dreaded complication of Percutaneous Coronary Intervention (PCI). It is associated with high morbidity and mortality rates. Though acute and subacute stent thrombosis is seen commonly, very late stent thrombosis (VLST) is also seen, and it does raise particular concerns. The reason being the lacunae in the understanding of its underlying pathophysiology and the dilemma in the optimal preventive strategies and durations of dual antiplatelet therapy after stent insertion. We report a case of VLST that occurred 5 years after stent insertion.

\section{Case report}

In 2018 November, 62 years old non hypertensive, non-diabetic, non-smoker male patient presented to our hospital with history of NonST Elevation Myocardial Infarction (NSTEMI). In 2013, the patient had undergone Percutaneous coronary angioplasty to Left Anterior Descending (LAD) artery $3.5 \times 24 \mathrm{~mm}$ Drug Eluting stent (DES) across an $80 \%$ stenosis in the proximal LAD. The stent had been deployed at a pressure of $14 \mathrm{~atm}$ without postdilation. The result was satisfactory with full expansion of the stent at an outside center. The patient was continued on dual antiplatelets $75 \mathrm{mg}$ once a day for one year and then switched over to single antiplatelet (aspirin) monotherapy at $75 \mathrm{mg}$ once a day, which the patient was taking till 3 days back. The patient stopped the aspirin for a minor non cardiac procedure- a routine that he had followed on multiple occasions with no adverse consequences.

At the current presentation, coronary angiograms revealed filling defect at the proximal edge of the sirolimus-eluting stent (SES) (Figure 1). Optical coherence tomograms (OCT) of the LAD confirmed it as a red thrombus, overlying substantial exposed unendothelized stent struts. There was no proximal edge malapposition of the DES and no restenosis secondary to neoatherosclerosis in the mid segment; and undisrupted neointimal formation in the distal segment of the stent (Figure 2). Since the thrombus was non occlusive, the patient was started on GP IIb/IIIa inhibitors and heparin for 5 days. After 5 days of good anticoagulation, the patient underwent check angiography, which revealed that the proximal end of the stent was clear of the thrombus. OCT confirmed complete disappearance of the thrombus with the anticoagulation (Figure 3). The patient recovered uneventfully and was discharged from the hospital with dual anti platelets (aspirin and ticagrelor).

\section{Discussion}

Very late stent thrombosis is defined as the development of thrombotic stent occlusion later than 12 months after stent insertion [1]. Few studies mention the incidence of VLST in DES from 0.4 to $0.6 \%$ annually after 12 months [2]. The specific risk factors for VLST are less well defined although current smoking, longer stent and lesion length have been reported as risk factors [3]. Higher numbers of stents per lesion and stent overlap are also prominent characteristics in patients with DES who sustain VLST [4]. Discontinuation of antiplatelet therapy has not been shown to be a risk factor for VLST [5].

There have been a few studies which showed similar stent thrombosis with sirolimus eluting stents after 11 years of implantation. The underlying pathophysiology may be a combination of delayed arterial healing, ongoing vessel inflammation, neo atherosclerosis, late stent malposition and under expanded stents. The minimal luminal diameter of our patient's proximal LAD was $3.2 \mathrm{~mm}$ so a constrained size of stent may also be a factor in our case.

\section{Mechanisms of stent thrombosis}

Incomplete endothelialization of stent struts is the primary precipitant of stent thrombosis. Other factors are late stent malposition

*Correspondence to: Ranjan Modi, Fortis Escorts Heart Institute, Okhla, New Delhi - 110025, India, Tel: 0984491710; E-mail: modi.ranjan@gmail.com

Key words: stent thrombosis, dual antiplatelets, coronary intervention, optical coherence tomography

Received: June 20, 2019; Accepted: July 05, 2019; Published: July 08, 2019 


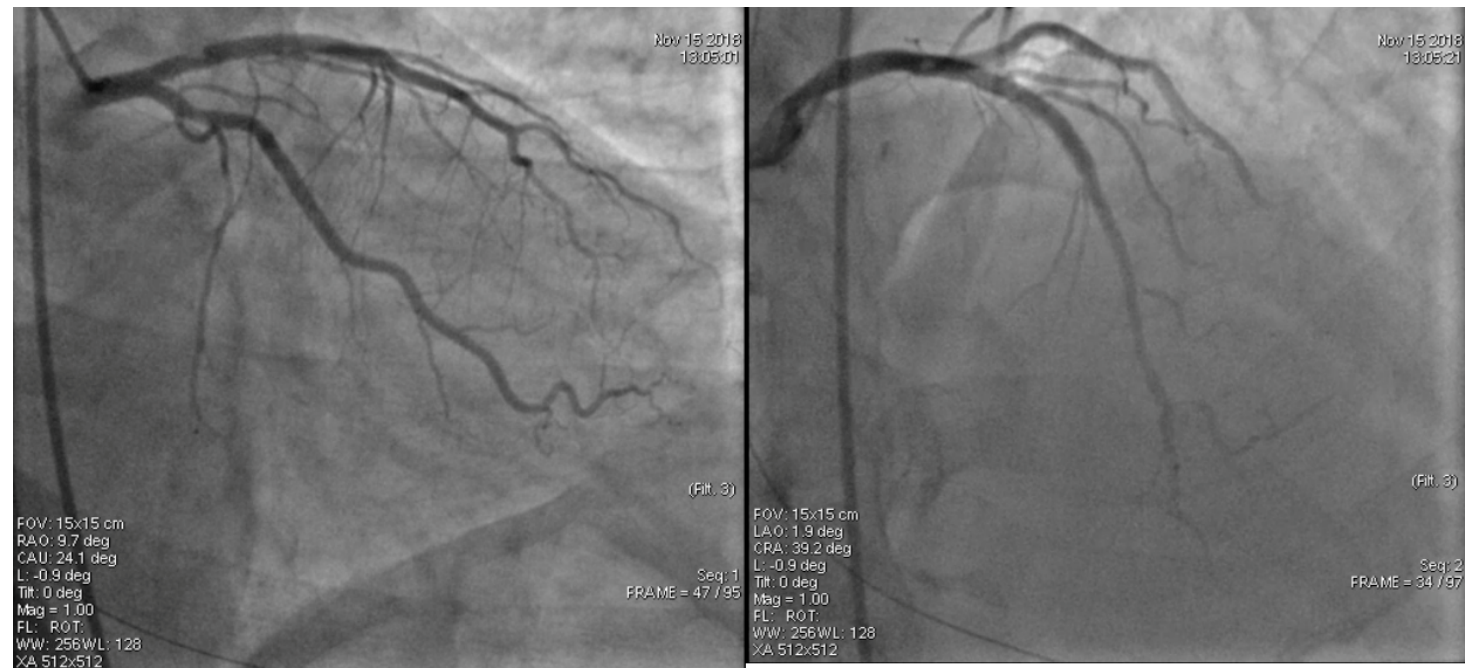

Figure 1. Coronary angiograms revealed filling defect at the proximal edge of the drug-eluting stent
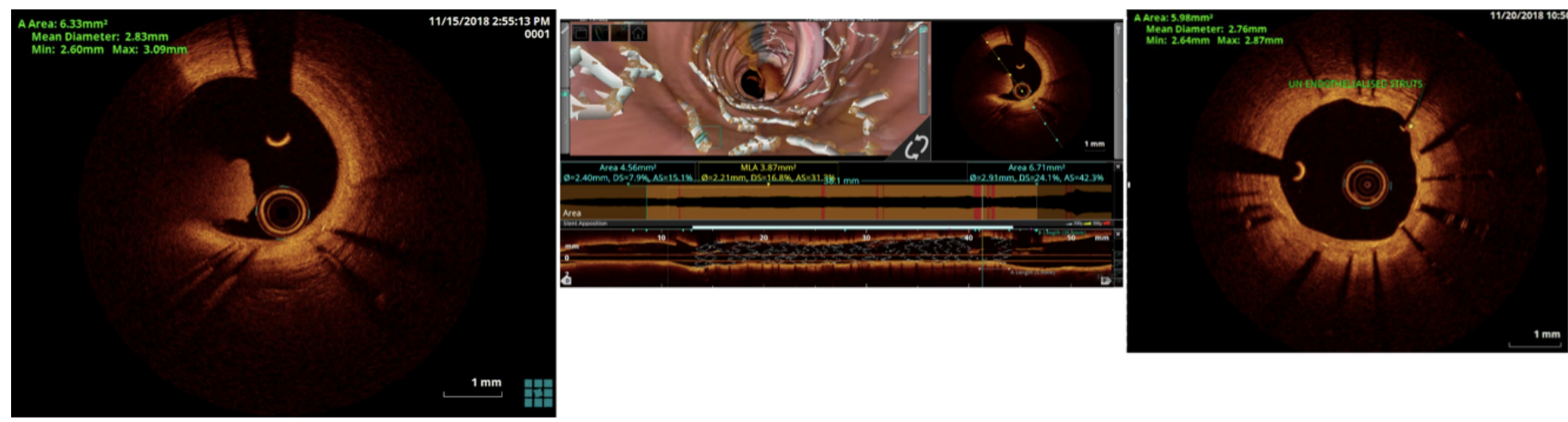

Figure 2. Pre-Optical coherence tomography of LAD with thrombus and unendothelised stent struts
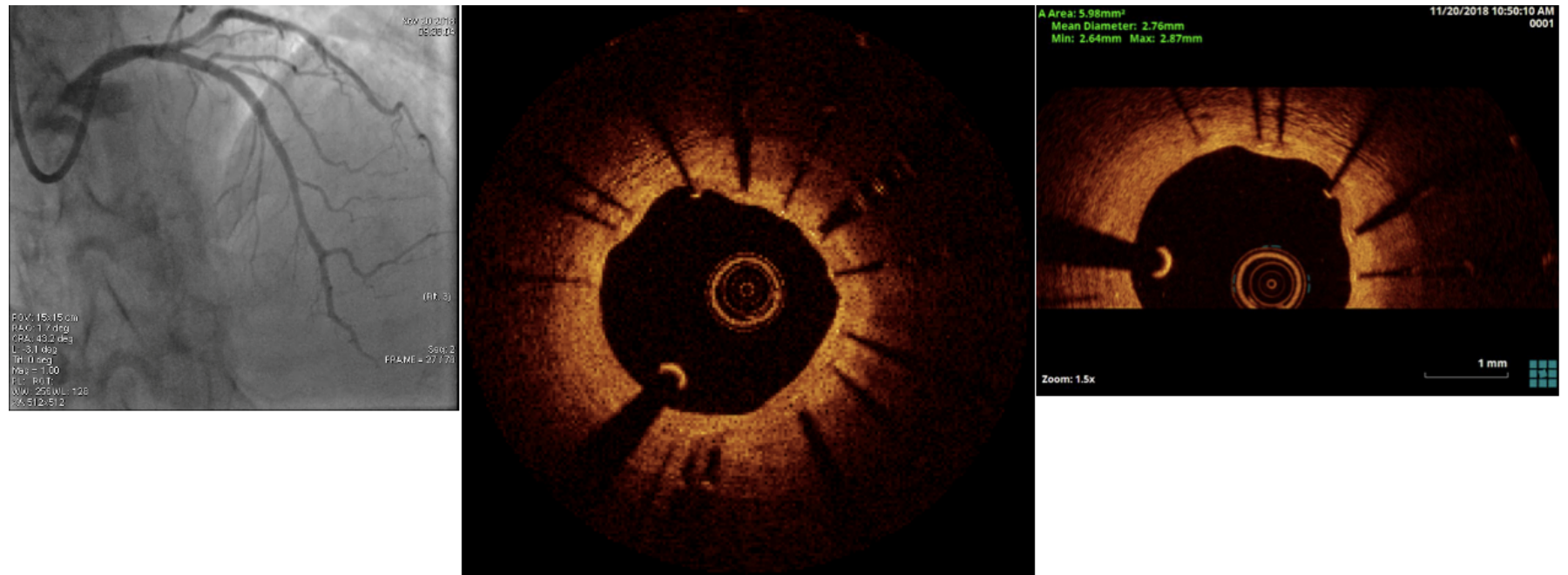

Figure 3. Post anticoagulation check angiography of LAD with optical coherence tomography

secondary to delayed positive remodeling, strut penetration into a necrotic core, and chronic vascular inflammation and hypersensitivity reaction to the metal struts [6,7]. Neoatherosclerosis has an increasingly recognized role in stent restenosis and VLST [8]. As a maladaptive endothelial response to stent implantation, neoatherosclerosis results in the evolution of a fibrous neointima into new in-stent atherosclerotic plaques. The mechanism underlying neoatherosclerosis might be a pathogenetic link with chronic inflammation [9]. As a group, DES tend to be associated with greater and earlier development of neoatherosclerosis than are bare-metal stents.

Finally, the incidence of thin cap fibroatheromas(TCFA) that contain neointima seem to increase with time, as does the presence of 
red thrombi associated with atheromatous plaque rupture. All these factors suggest that neoatherosclerosis substantially contributes to VLST.

\section{Implication of optical coherence tomography and neointimal characterization}

OCT has better enabled clinician to view and evaluate endothelial response after stent implantation. Kang and colleagues [10] used OCT to identify prevalent TCFA containing neointima, in-stent neointimal rupture, and intraluminal thrombi within DES. The investigator found that $52 \%$ of the lesions had at least one TCFA containing neointima, $58 \%$ had in-stent neointimal rupture, and 58\% had intraluminal thrombi at the end of 3 years. Of more importance was an association between clinical instability and OCT findings of instability.

In the evaluation of previously implanted stents, OCT enables clinicopathologic correlation and provides diagnostic and prognostic information beyond that of conventional angiography. Our patient had no high-risk clinical features that would have predisposed him to the development of VLST: he was a non-diabetic, non-smoker who had a single stent implanted across a relatively short disease arterial segment. The focal non endothelialized struts of the stent seen on OCT would imply its role in the pathogenesis of our patient's VLST, also the patient was on single antiplatelet therapy for last many years which he had discontinued since last 3 days.

\section{Conclusion}

The case of VLST highlights the lacunae in understanding of endothelization and stent thrombosis. It also points to deficiencies in the overall risk stratification of patient peri and post intervention. The treatment strategies required for such patients should be an individualized approach based on clinical judgment and proper risk stratification.

\section{References}

1. Cutlip DE, Windecker S, Mehran R, Boam A, Cohen DJ, et al. (2007) Clinical end points in coronary stent trials: a case for standardized definitions. Circulation 115: 2344-2351. [Crossref]

2. Wenaweser P, Daemen J, Zwahlen M, van Domburg R, Jüni P, et al. (2008) Incidence and correlates of drug-eluting stent thrombosis in routine clinical practice: 4-year results from a large 2-institutional cohort study. J Am Coll Cardiol 52: 1134-1140. [Crossref]

3. Kimura T, Morimoto T, Nakagawa Y, Kawai K, Miyazaki S, et al. (2012) Very late stent thrombosis and late target lesion revascularization after sirolimus-eluting stent implantation: five-year outcome of the j-Cypher Registry. Circulation 125: 584-591. [Crossref]

4. Cook S, Wenaweser P, Togni M, Billinger M, Morger C, et al. (2007) Incomplete stent apposition and very late stent thrombosis after drug-eluting stent implantation. Circulation 115: 2426-2434. [Crossref]

5. Schulz S, Schuster T, Mehilli J, Byrne RA, Ellert J, et al. (2009) Stent thrombosis after drug-eluting stent implantation: incidence, timing, and relation to discontinuation of clopidogrel therapy over a 4-year period. Eur Heart J 30: 2714-2721. [Crossref]

6. Nakazawa G, Finn AV, Vorpahl M, Ladich ER, Kolodgie FD, et al. (2011) Coronary responses and differential mechanisms of late stent thrombosis attributed to firstgeneration sirolimus-and paclitaxel-eluting stents. J Am Coll Cardiol 57: 390-398. [Crossref]

7. Nakazawa G, Finn AV, Joner M, Ladich E, Kutys R, et al. (2008) Delayed arteria healing and increased late stent thrombosis at culprit sites after drug-eluting stent placement for acute myocardial infarction patients: an autopsy study. Circulation 118: 1138-1145. [Crossref]

8. Park SJ, Kang SJ, Virmani R, Nakano M, Ueda Y (2012) In-stent neoatherosclerosis: a final common pathway of late stent failure. J Am Coll Cardiol 59: 2051-2057. [Crossref]

9. Inoue K, Abe K, Ando K, Shirai S, Nishiyama K, et al. (2004) Pathological analyses of long-term intracoronary Palmaz-Schatz stenting: Is its efficacy permanent? Cardiovasc Pathol 13: 109-115. [Crossref]

10. Kang SJ, Mintz GS, Akasaka T, Park DW, Lee JY, et al. (2011) Optical coherence tomographic analysis of in-stent neoatherosclerosis after drug-eluting stent implantation. Circulation 123: 2954-2963. [Crossref]

Copyright: (C2019 Chandra N. This is an open-access article distributed under the terms of the Creative Commons Attribution License, which permits unrestricted use, distribution, and reproduction in any medium, provided the original author and source are credited. 